\title{
Measuring the effectiveness of regional conservation assessments at representing biodiversity surrogates at a local scale: A case study in Réunion Island (Indian Ocean)
}

\author{
KARINE PAYET, ${ }^{1 \star}$ MATHIEU ROUGET ${ }^{2}{ }^{\text {ERWANN }}$ LAGABRIELLE ${ }^{3}$ AND \\ KAREN J. ESLER ${ }^{4}$ \\ ${ }^{1}$ Biodiversity Planning Unit, SANBI, Kirstenbosch Research Centre, Private Bag X7, Claremont, 7735, \\ South Africa; Department of Conservation Ecology \& Entomology, Faculty of AgriSciences, Stellenbosch \\ University, Private Bag x1, Matieland, 7602, South Africa (Email: karine.kp@gmail.com); \\ ${ }^{2}$ Biodiversity Planning Unit, SANBI, Private Bag x101, Pretoria, South Africa; ${ }^{3} U M R$ PVBMT, \\ Université de la Réunion, Cirad, 7 chemin de l'Irat, Ligne paradis, 97410 Saint-Pierre, France and \\ Botany Department, Nelson Mandela Metropolitan University, Saasveld Campus, Private Bag X6531, \\ George 6530, South Africa; and ${ }^{4}$ Department of Conservation Ecology \& Entomology and Centre for \\ Invasion Biology, Faculty of AgriSciences, Stellenbosch University, Private Bag x1, Matieland 7602, \\ South Africa
}

\begin{abstract}
In a context of scarce financial and human resources, the allocation of conservation efforts needs to be optimized. Our analysis attempts to draw conclusions on the integration of regional and local conservation assessments, specifically, with regard to the acquisition of fine-scale data to complement the regional assessment. This study undertaken in Réunion Island (Indian Ocean) assessed how biodiversity surrogates targeted at a regional scale represented other biodiversity surrogates at a local scale. Biodiversity surrogates at both scales consisted of species, habitats and processes. Habitats and processes at regional scale were defined using a coarser scale of thematic resolution than at local scale. The surrogacy was tested in terms of incidental representation of local-scale features in the regional assessments, and correlation of irreplaceability values between scales. Near-minimum sets and irreplaceability values were generated using MARXAN software. Our results revealed that conservation targets for processes at local scale were never met incidentally, while threatened species and fragmented habitats were also usually under-represented. More specifically, requiring only $12 \%$ of the local planning domain, the application of species as surrogates at regional scale was the least effective option at representing biodiversity features at local scale. In contrast, habitats at a coarse scale of thematic resolution achieved a significant proportion of conservation targets incidentally $(67 \%)$ and their irreplaceability values were well correlated with the irreplaceability values of surrogates at local scale. The results highlighted that all three types of biodiversity surrogates are complementary for assessing overall biodiversity. Because of the cost of data acquisition, we recommended that the most efficient strategy to develop nested regional/local conservation plans is to apply habitats and processes at a coarse scale of thematic resolution at regional scale, and threatened species and degraded habitats at local scale, with their fine-scale mapping limited to highly transformed areas.
\end{abstract}

Key words: coarse/fine filters, habitat transformation, spatial scale, surrogacy analysis, systematic conservation planning, thematic resolution.

\section{INTRODUCTION}

Conservation ambitiously aims to preserve all biodiversity (Noss 1990; Sarkar 2002), but past approaches to conservation planning have produced systems of conservation areas that contain a biased sample of

\footnotetext{
${ }^{\star}$ Corresponding author. Present address: Department of Conservation Ecology \& Entomology, Faculty of AgriSciences, Stellenbosch University, Private Bag x1, Matieland, 7602, South Africa. (Email: karine.kp@gmail.com)

Accepted for publication March 2009.
}

biodiversity (Margules \& Pressey 2000). Thus, systematic approaches have been developed to identify and implement networks of priority areas that preserve a representative and persistent sample of all biodiversity patterns and processes (Cowling et al. 1999). Here, we focus on the technical phase of a systematic conservation plan that deals with the identification of priority areas, viz. the conservation assessment (Knight et al. 2006).

A systematic conservation assessment uses measurable variables that serve as surrogates for all 
biodiversity and help in the process of comparing and prioritizing areas based on their biological value (Margules \& Pressey 2000; Sarkar et al. 2002). But there is no consensus among conservationists on which surrogates are best (see Brooks et al. 2004b,c; Cowling et al. 2004; Higgins et al. 2004; Molnar et al. 2004; Pressey 2004). Some authors have emphasized the relevance of using environmental surrogates (i.e. surrogates defined on abiotic data, e.g. climate, sometimes combined with biotic information, e.g. vegetation types) to secure biodiversity patterns and processes at all levels of biological organization (e.g. Higgins et al. 2004; Pressey 2004; Sarkar et al. 2006), while other authors argue that species datasets are first-order information to priority-setting because species are regarded as the core component of biodiversity (e.g. Brooks et al. 2004c; Hortal \& Lobo 2006). Many scientific studies have also advocated using composite datasets (Kiester et al. 1996; Lombard et al. 1997; Reyers et al. 2002; Stoms et al. 2005), and, since recently, some authors have included explicit surrogates for ecological and evolutionary processes (Cowling \& Pressey 2001; Rouget et al. 2003). Finally, georeferenced and quantitative data must be used (Margules \& Pressey 2000); yet these are usually available only for a few welldocumented biodiversity features (Brooks et al. 2004a; Sarkar et al. 2005). Thus, conservation planners also often have to make the best use of available datasets (Noss 2002).

The debate on which biodiversity surrogates are the most appropriate to use has remained unsettled largely because the question cannot be assessed rigorously by empirical research (Sarkar et al. 2006). The effectiveness of a biodiversity surrogate refers to its ability to ensure an adequate representation of other biodiversity features (Sarkar et al. 2005). Because there is no measure of global biodiversity against which effectiveness can be assessed comprehensively (Sarkar 2002), scientists test how well a set of known biodiversity features can represent another set (Sarkar \& Margules 2002). In addition, the shortcomings of data quality and availability (Ferrier 2002; Crane et al. 2003) often generate findings of dubious value (Larsen \& Rahbek 2005), while the comparison of results across regions is impossible because of the lack of site duplication and the variety of methods employed (Reyers \& van Jaarsveld 2000). Thus, surrogacy analyses typically provide a partial and equivocal empirical assessment of the problem of global biodiversity representation.

Nonetheless, research on biodiversity surrogacy should ultimately formulate useful recommendations to conservation planners on which data to compile depending on available time and resources (Stoms et al. 2005). In particular, a fine-scale conservation assessment is generally costly and often only affordable over limited areas (Rouget 2003), so a 'hierarchy of priority setting' (sensu Mittermeier et al. 1998) is often applied where coarse-scale assessments of larger areas guide the allocation of finer-scale efforts in smaller areas (Driver et al. 2003; Ferrier et al. 2004). Meanwhile, little attention has been dedicated to understanding how conservation assessments at multiple scales could be integrated. To direct conservation planning efforts optimally between scales of application, one may question how effectively a regional assessment serves as a basis for local planning, and analyse what biodiversity information should gain fine-scale mapping effort. With the exception of the framework provided by The Nature Conservancy (Poiani et al. 2000) and the few existing recommendations (e.g. Driver et al. 2003), there is an overall lack of studies that provide insights on this issue.

Studies dealing with scale have traditionally focused on spatial extent and resolution, although thematic resolution, viz. the level of detail of a map classification, is another intrinsic component of scale (Castilla et al. 2009). Recent studies in landscape ecology have demonstrated that thematic resolution significantly affects landscape patchiness (increases with finer scale of thematic resolution) and the outcomes of landscape pattern analyses (e.g. Baldwin et al. 2004; Bailey et al. 2007; Castilla et al. 2009). For conservation, a focus on thematic resolution has the potential to highlight what level of ecological detail is of importance in priority setting. Then, whether or not the ecological features can be mapped at fine spatial resolution is a technical matter that will depend on affordability.

This paper analyses what type of data should gain fine-scale mapping effort for the assessment of a small planning domain (i.e. the local scale), so that information is complementary to the coarse-scale assessment performed for a larger planning domain (i.e. the regional scale). An initiative to introduce systematic conservation planning on Réunion Island (Lagabrielle 2007) presented an opportunity to investigate this question. We assessed two nested domains with different combinations of datasets on terrestrial biodiversity. Each dataset was composed of the three main types of biodiversity surrogates, that is, species, habitats, and ecological and evolutionary processes. We analysed the extent to which priority areas identified at regional scale represented the biodiversity surrogates at local scale and discuss the consequences of the choice of biodiversity surrogates targeted in regional and local conservation assessments. This study was based on the assumption that when a regional assessment adequately represented biodiversity features in a local planning domain, the resources needed for the acquisition of the dataset at local scale could have been spent on another element of the conservation assessment. This rule supports the increase in the optimization of conservation effort allocation (Wilson et al. 2006). 


\section{METHODS}

\section{Study area}

Réunion Island $\left(21^{\circ} \mathrm{S}, 55^{\circ} \mathrm{E}\right)$ is a volcanic island of the Mascarene Archipelago, in the Indian Ocean (see box in Fig. 1). It is $2512 \mathrm{~km}^{2}$ in extent and the climate is humid tropical. There is an active volcano (Piton de la Fournaise, $2631 \mathrm{~m}$ a.s.1.) in the south-east. The island is furrowed by deep ravines and culminates at $3070 \mathrm{~m}$ a.s.1. (Piton des Neiges) in the centre. This sharp relief supports a thermal altitudinal gradient (mean temperatures vary between $21^{\circ} \mathrm{C}$ in winter and $26^{\circ} \mathrm{C}$ in summer on the coast, and respectively, between $12^{\circ} \mathrm{C}$ and $17^{\circ} \mathrm{C}$ at about $1500 \mathrm{~m}$ ), a highly contrasting eastwest rainfall gradient (mean annual rainfall is $>6 \mathrm{~m}$ in the east to $<1.5 \mathrm{~m}$ in the west) and zones of diversified microclimates. Habitat types are structured along the altitudinal and rainfall gradient, from littoral grass prairie to alpine shrublands through evergreen forests or savannas (Cadet 1980; Strasberg et al. 2005). Plant species richness is relatively low but the level of endemism is high (Jacquemyn et al. 2005), and some oceanic birds are known to reproduce on the island only (Le Corre et al. 2002).

Réunion Island is part of the Madagascar biodiversity hotspot for its high endemism and habitat loss (Myers et al. 2000). Habitat transformation (including alien plant invasion) on Réunion Island is estimated at $73 \%$ of the area and is concentrated in the more accessible lowlands (Fig. 1). Invasion by alien species and land transformation by clearing and human population growth are currently very high and still increasing (Strasberg et al. 2005; Baret et al. 2006). In this context of increasing pressures, the challenge for biodiversity conservation on Réunion Island must be addressed rapidly and efficiently.

\section{Study design}

In accordance with a systematic conservation assessment protocol (Margules \& Pressey 2000; Knight et al. 2006), we mapped the local and regional planning domains and divided them up into planning units; we compiled geographic information system (GIS) maps on the distribution of biodiversity surrogates and assigned a quantitative conservation target to each feature; and we identified near-minimum sets with the conservation planning software MARXAN (Ball \& Possingham 2000) and CLUZ (Smith 2004), to represent surrogates at target level. A robust systematic conservation planning exercise requires that existing reserves and contextual parameters, such as socio-economic variables, are taken into consideration (Margules \& Pressey 2000). Such parameters influence the selection process and would have made it difficult to distinguish between their effect and the effect of the biological data on the selection outcomes. They were therefore not included in our surrogacy analysis.

We measured surrogacy based on the incidental representation in near-minimum sets (Fig. 2a) and on the spatial correlation between patterns of irreplaceability values (Fig. 2b). The near-minimum set method assessed the level of target achievement in one good configuration of priority

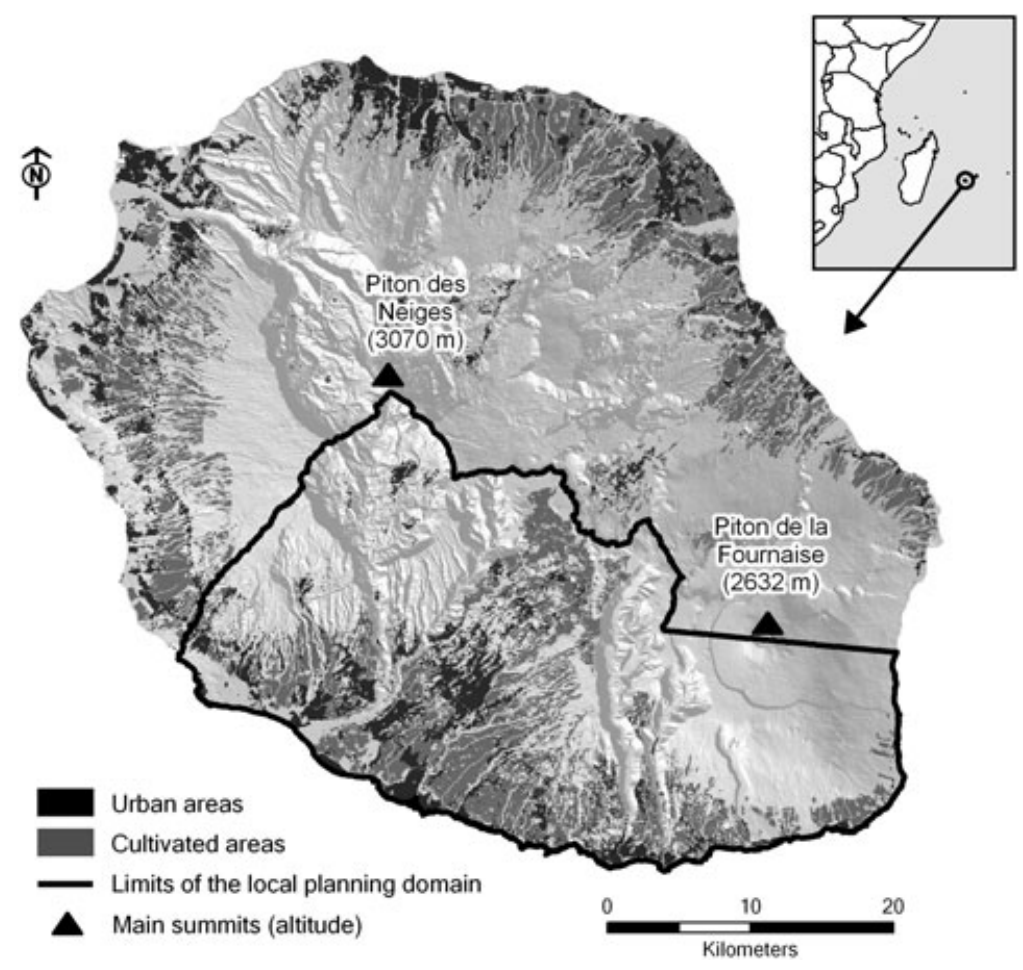

Fig. 1. Patterns of habitat transformation in Réunion Island. Both planning domains analysed in this study are the whole island (i.e. the regional planning domain) and the area delimited by the thick black line (i.e. the local planning domain). 
(a)

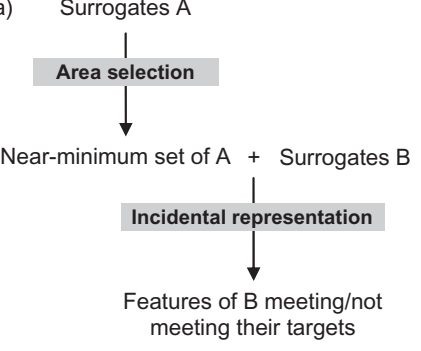

(b)

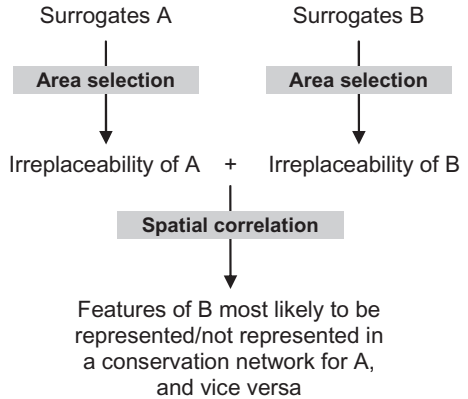

Fig. 2. Near-minimum set (a) and irreplaceability (b) approaches used for the surrogacy analysis. In the near-minimum set approach, we measured the proportion of biodiversity features at a local scale, B, that incidentally reached their conservation target in a near-minimum set selected for biodiversity surrogates targeted at a regional scale, A. In the irreplaceability approach, we analysed how the irreplaceability values obtained with A, were spatially correlated to the irreplaceability values obtained with B.

Table 1. Biodiversity surrogates used at regional and local scale

\begin{tabular}{|c|c|c|c|}
\hline & & $\begin{array}{l}\text { Targets in } \% \text { of } \\
\text { current extent }\end{array}$ & $\begin{array}{l}\% \text { of planning } \\
\text { units with records }\end{array}$ \\
\hline \multicolumn{4}{|c|}{ Regional scale } \\
\hline Habitats & Six habitat types (Strasberg et al. (2005) & 20 to $>100$ & $48^{\natural}$ \\
\hline \multirow[t]{2}{*}{ Species } & Eight threatened vascular plant species $\left(\mathrm{CBNM}^{\dagger}\right)$ & 100 & $61^{\Uparrow}$ (all species) \\
\hline & $\begin{array}{l}\text { Sixteen vertebrate species or species assemblages } \\
\text { (SEOR }{ }^{\ddagger}, \text { Nature et Patrimoine) }\end{array}$ & $\begin{array}{l}20(n=4), 40(n=7) \\
\quad \text { or } 100(n=5)\end{array}$ & \\
\hline Processes & Five processes (Lagabrielle (2007) & 100 & $40^{\pi}$ \\
\hline \multicolumn{4}{|l|}{ Local scale } \\
\hline Habitats & Eighteen habitat types (Strasberg et al. (2005) & 8 to $>100$ & 47 \\
\hline Species & $\begin{array}{l}\text { Nineteen vascular plant species or species assemblages } \\
\text { (E. Rivière }{ }^{\S} \text {, unpublished data, 2007) }\end{array}$ & $\begin{array}{l}20(n=9), 30(n=2) \\
\quad 40(n=1) \text { or } 100(n=7)\end{array}$ & 83 \\
\hline Processes & Six processes (Lagabrielle (2007) & 100 & 43 \\
\hline
\end{tabular}

${ }^{\dagger}$ Conservatoire Botanique National des Mascarins. ${ }^{\ddagger}$ Société d'Etudes Ornithologiques de la Réunion. ${ }^{\circledR}$ CIRAD, chemin de l'Irat, 97410 Saint-Pierre, Réunion, riviere@cirad.fr. "Percentages are the same within the extent of the regional and the local planning domain.

areas identified among others; the irreplaceability method, on the other hand, assessed the probability of target achievement across the whole planning domain (Pressey et al. 1994; Lombard et al. 2003; Warman et al. 2004b).

\section{Planning domains and planning units}

We delineated the local planning domain with municipal boundaries (Erasmus et al. 1999); this planning domain consisted of approximately one-third $\left(943 \mathrm{~km}^{2}\right)$ of the extent of the whole island, itself being the regional planning domain (Fig. 1).

The comparison of the biodiversity value of sites one to another is usually performed by dividing planning domains into elementary building blocks called planning (or selection) units (Pressey \& Logan 1998). We divided up both planning domains in hexagonal planning units (10.39 ha each). The hexagons were identical in size, orientation and position for both planning domains. We obtained 9378 units at the local scale nested within the 24630 units of the regional scale. Choosing different planning units influence the selection process (Rodrigues \& Gaston 2001; Warman et al. 2004b).

\section{Biodiversity surrogates}

At each scale, the datasets comprised of the three main types of biodiversity surrogates applied in conservation assessments, that is: (i) the distribution range of natural habitat types (hereafter, habitats); (ii) the distribution of individual species or species assemblages (hereafter, species); and (iii) the spatial patterns of ecological and evolutionary processes (hereafter, processes; Table 1). The maps of habitats and processes used at the regional and local scale, respectively, differed in scale of thematic resolution in order to assess where more detailed ecological information was needed at local scale. The species datasets, however, could not be tested likewise. We obtained existing GIS maps from biodiversity organizations or generated new ones using expert knowledge (see Table 1 and Acknowledgments for the sources).

We assigned a quantitative conservation target, that is, the minimum amount (in terms of number of occurrences or areas of land) to be included in the priority areas (Pressey et al. 2003), to each biodiversity feature. There is no universal and perfect way to set conservation targets (Sarkar et al. 2006). Here, we followed some premises of the approach of 
Pressey et al. (2003) to define percentage targets scaled to reflect differences in apparent requirements for protection of each biodiversity feature. We inferred the targets on considering environmental and biological heterogeneity for habitats, and natural or induced rarity and vulnerability criteria for species. High values for these parameters reflected higher requirements for protection, and therefore higher conservation targets.

\section{Habitats}

Strasberg et al. (2005) derived a map of habitats for Réunion Island in a two-tier classification. The first tier comprised six habitat types derived from the typology of Cadet (1980). They derived the second-tier habitat types mainly on climate, topography and geology, using information from the literature, expert knowledge and remote-sensed data. We used the six habitat types of the first tier at the regional scale; and the 19 habitat types of the second tier at the local scale, 18 of which were represented in the local planning domain (Table 1). Similarly, Baldwin et al. (2004) and Bailey et al. (2007), who examined the effect of thematic resolution on landscape metrics, used their respective land cover map at different tiers of its classification.

Conservation targets for habitats were derived as percentages of their original extent. We classified habitats of the first tier of the classification, except for wetlands, in two groups according to their environmental heterogeneity (i.e. factors on altitude, slope, local relief, soil type and precipitation) and attributed a percentage target of $20 \%$ and $30 \%$ to the least $(n=2)$ and the most $(n=3)$ heterogeneous habitats, respectively. We classified the second-tier habitats, except for wetlands, in quartiles according to their environmental heterogeneity (same as above), level of plant species endemism and level of plant species richness. We assigned a percentage target of $10 \%, 20 \%$ and $30 \%$ to the habitats falling in the lowest $(n=4)$, both intermediate $(n=8)$ and the highest $(n=5)$ scoring quartiles, respectively. Wetlands of both tiers were assigned a target of $100 \%$, based on the assumption that their ecological sustainability relied on their maximum integrity. We converted percentages into areas calculated from the habitats' original extents modelled by Strasberg et al. (2005) (Table 1).

\section{Species}

All species were indigenous and some strictly endemic to the island. At both scales, the species datasets were incomplete and biased towards specific taxa. However, this represents the best species spatial data available for the island. Incomplete biodiversity datasets unfortunately remains a challenge to most conservation assessments (Sarkar et al. 2006). Species at the regional scale consisted of both plants and vertebrates (Table 1). Data on plants were locality records of eight threatened species, whose threat status had been determined by the Conservatoire Botanique National de Mascarin (2007) (CBNM, http://flore.cbnm.org) using the same categories and criteria as the 2001 IUCN Red List Categories \& Criteria version 3.1. Data on vertebrates comprised locality records (four species) or distribution ranges (12) for one bat, two reptiles, eight forest birds, two forest bird species assemblages and nesting sites of two oceanic birds and one oceanic bird species assemblage. The bat, both oceanic birds and two forest birds were IUCN Red List threatened species (IUCN Red List version 3.1, IUCN 2007). An association of local ornithologists (Société d'Etudes Ornithologiques de la Réunion, http://www.seor.fr) had also assigned a high conservation priority status to some of the species.

The use of point localities may be more characteristic of local than regional planning. Nevertheless, our use of point localities is not atypical, as they have been applied in priorityarea setting in planning domains larger than our regional domain (e.g. Lombard et al. 2003). Thus, the fact that point localities for species can be available over rather large areas implies that they may or may not be applied in regional planning. More to the point, in the case of oceanic islands, that are small size territories $\left(<10000 \mathrm{~km}^{2}\right.$; Lagabrielle 2007), point localities may often be accessible at island scale and used in a preliminary assessment for regional planning. Here, we therefore decided to use the species point localities at the scale at which they were available. This methodological choice has a minor consequence on the whole analysis, as our species point localities occupied only $<1.5 \%$ of planning units in the local planning domain.

The dataset applied at local scale consisted of plants only. This was the distribution ranges of 19 plant species or plant species assemblages or communities (Table 1) that we mapped at a fine-scale of spatial resolution $(-1 / 8000)$ on local expert knowledge. Two of these species were listed as threatened by the IUCN (Red List version 2.31994 , IUCN 2007) and five other species were assessed as threatened by the CBNM. Three threatened coastal plant species (Delosperma napiforme, Chamaesyce viridula and Pemphis acidula) were represented at both scales, but their distribution ranges overlapped partly, highlighting the incompleteness of the respective datasets.

We calculated species targets as a proportion of their known current distribution, given that we had no information on their original distribution. We used the criteria of endemicity/rarity, threat and conservation priority to assign the percentage targets (Table 1).

\section{Processes}

Protocols have been proposed in South Africa on how largescale processes can be integrated into conservation assessments (e.g. Cowling et al. 1999; Desmet et al. 2002; Cowling et al. 2003). We followed them here to identify, map and select areas for the representation of their spatial components in priority areas (see Lagabrielle 2007 for more details).

Five major spatial components of processes that sustain the ecological and evolutionary persistence of the insular biodiversity of Réunion Island were mapped at regional scale. These were lowland-upland gradients that sustain plant diversification (Warren et al. 2006) and seasonal feeding migrations of birds and insects (in Lagabrielle 2007); oceanic-terrestrial interface that supports the feeding of marine birds nesting inland (Le Corre \& Safford 2001) and species colonization (Cadet 1980); isolated topographic units for the allopatric diversification of taxa (in Lagabrielle 2007); riverine corridors of perennial rivers that support top-down 
nutrient flows and bird movements (Le Corre \& Safford 2001); and interfaces between habitats of the first tier of the classification for plant and animal lineages diversification (Cadet 1980). For the local assessment, we added the riverine corridors of the non-perennial rivers and replaced the first-tier habitat interfaces by the second-tier habitat interfaces. Hence, there were five processes at regional scale and six at local scale, four being common to both scales (Table 1). They were targeted at $100 \%$ of their extant areas because we assumed that their persistence, and the biodiversity that relies on, depends on their full integrity.

\section{The selection of priority areas}

We selected sets of planning units that represented the biodiversity surrogates at their target level within the smallest possible area, i.e. based on the efficiency principle (Pressey \& Nicholls 1989; Pressey \& Logan 1998). This is best performed by selecting areas that are the most complementary in the biodiversity features they contain (Pressey et al. 1993). Complementarity-based area-selections identify solutions called minimum or near-minimum sets (Pressey et al. 1997; Pressey \& Taffs 2001). They have widely been used in real-world conservation planning (Justus \& Sarkar 2002).

We used the simulated annealing algorithm embedded in MARXAN conservation planning software (Ball \& Possingham 2000), with its CLUZ interface (Smith 2004), to identify near-minimum sets (hereafter minsets). Constraint rules that can be fixed in MARXAN software, such as parameters for cost and design criteria were not used here. We produced the minsets by targeting habitats (minset $\mathrm{H}$ ), species (S) and processes (P) separately and assembled (viz. habitats and species (HS), habitats and processes $(\mathrm{HP})$, species and processes (SP), and habitats, species and processes (HSP)), at each scale. For each combination, we obtained a suite of 200 and 150 minsets at regional and local scale, respectively, to account for the size of each planning domain.

\section{The surrogacy analysis}

For the surrogacy analysis, we used the regional best (i.e. the most efficient) minset of each suite for approach (a) in Figure 2. For approach (b) in Figure 2, we used the MARXAN output called the 'summed solution'. This is the summary of the total number of times each planning unit is selected in a suite. Hence, the summed solution approximates how necessary each planning unit is to achieve conservation targets, which can be interpreted as a measure of its irreplaceability in the absence of implementation constraints (Ball \& Possingham 2000; Ferrier et al. 2000). We analysed the seven summed solutions produced at each scale. We clipped the regional minsets and summed solutions to the local planning domain boundaries in ArcView 3.2 (ESRI, Redlands, CA, USA). All further comments and discussion are therefore relevant to the extent of the local planning domain only, except if specified otherwise.

\section{The minset approach}

We compared the seven regional minsets one to another in terms of (i) the biodiversity surrogates at local scale that were incidentally represented at target level; and (ii) the total areas selected (Reyers \& van Jaarsveld 2000; Lombard et al. 2003). We also assessed the total areas selected in regional minsets against the total areas selected in local minsets. There is incidental representation when the selection based on a given biodiversity surrogate also insures the representation of nontargeted biodiversity features (Warman et al. 2004a). In the case of five local-scale habitats that had targets larger than their remaining extent, targets were considered achieved when the total remaining area was selected. In addition, there was incidental representation for processes only for the riverine corridors of non-perennial rivers and the second-tier habitat interfaces. A good regional minset was one that achieved targets for a larger number of surrogates at the local scale and in a smaller total area selected, following the efficiency principle (Pressey \& Nicholls 1989; Pressey \& Logan 1998).

We performed 20 random selections of planning units of the same number of planning units selected as in the regional minsets. We compared the random selection that achieved the highest number of targets to their corresponding regional minset (e.g. Rodrigues et al. 2000). These comparisons indicate whether the regional conservation assessments perform better than randomly selecting units in achieving targets for biodiversity features at local scale.

\section{The irreplaceability approach}

The implementation of conservation priority areas often happens over prolonged periods and requires spatial flexibility (Pressey \& Taffs 2001; Pence et al. 2003). The irreplaceability value of planning units provides information on spatial options for the achievement of conservation targets (Ferrier et al. 2000). We assessed the level of spatial correlation between the regional and the local irreplaceability values using Spearman's rank correlation coefficients (R Development Core Team 2007). The assumption here is that where patterns of irreplaceability values for one surrogate are spatially similar to patterns of irreplaceability values for another surrogate, a conservation assessment for either surrogate is likely to incidentally represent the other surrogate in a final conservation network (Warman et al. 2004b). In contrast, if there is low or no similarity, it is likely that priority areas identified for both surrogates would complement each other (Margules et al. 2002) and both surrogates should be included to ensure their adequate representation in the final network of priority areas.

\section{RESULTS}

\section{The minset approach}

\section{Incidental representation and area selected}

Five $(13 \%)$ to $30(77 \%)$ of biodiversity features at local scale incidentally met their targets in the regional 
Table 2. Percentage of area selected per regional and local minset relative to the local planning domain extent

\begin{tabular}{lcc}
\hline & Regional minsets & Local minsets \\
\hline H & 22 & 22 \\
S & 12 & 17 \\
P & 40 & 43 \\
HS & 25 & 23 \\
HP & 43 & 47 \\
SP & 40 & 44 \\
HSP & 43 & 47 \\
\hline
\end{tabular}

Each minset is indicated by (a) letter(s) with $\mathrm{H}$ for habitats, $\mathrm{S}$ for species and $\mathrm{P}$ for processes of the surrogates used for the area-selection.

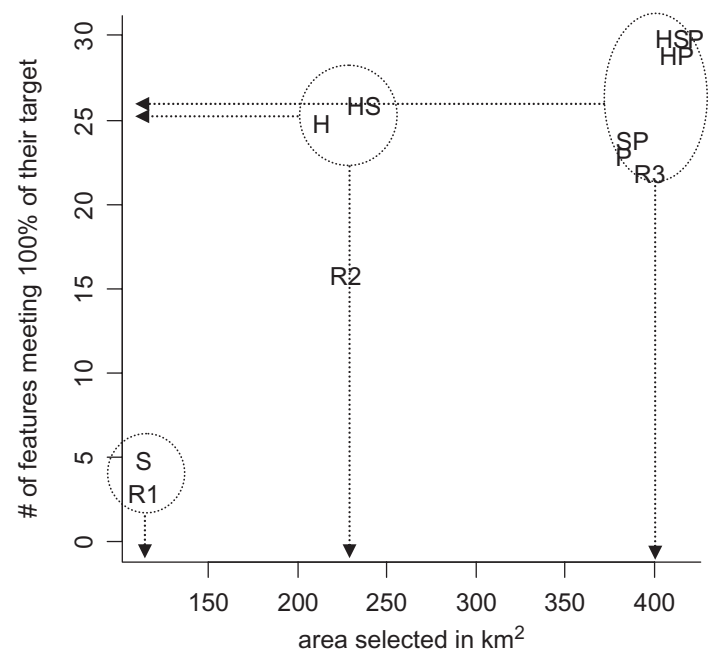

Fig. 3. Number of surrogates at the local scale meeting their targets by incidental representation in the regional minsets. Each minset is indicated by (a) letter(s) with $\mathrm{H}$ for habitats, $\mathrm{S}$ for species and $\mathrm{P}$ for processes of the surrogates used for the area-selection. Three groups of minsets are distinguishable in terms of total area selected (circled on the figure) and two in terms of incidental representation at target level ( $\mathrm{S}$ separate from the others). R1, R2 and R3 are random selections of planning units obtained for the same total area selected as the average area selected by the three groups.

minsets. Targets for processes were never incidentally met. The total area selected ranged from $12 \%$ to $43 \%$ of the planning domain. The area selected by each regional minset was comparative to the area selected by its analogous local minset (Table 2).

On the Figure 3 (excluding the three random selections), three groups of regional minsets were apparent on the selected area axis (x axis), but only two on the target achievement axis (y axis). The minset targeting species (S) by itself formed one group that achieved both, minimal incidental target achievement and smallest area selected (Fig. 3, see also Fig. 4 for a representation). In addition, targeting species in combination with other surrogates at regional scale, only marginally improved the incidental representation of features at local scale. Hence, regional scale species were relatively inefficient surrogates for local-scale biodiversity features.

All regional minsets targeting processes (i.e. P, HP, SP and HSP) achieved relatively high incidental target achievement for both local-scale species (58\% to $79 \%$ of them reaching their targets) and habitats $(67 \%$ and $83 \%)$, but were also the most land-hungry selections (Fig. 3, see also Fig. 4), requiring between $40 \%$ and $43 \%$ of the planning domain $\left(>400 \mathrm{~km}^{2}\right.$, Fig. 3). The regional minset targeting habitats $(\mathrm{H})$ performed comparative levels of incidental target achievement $(68 \%$ of local-scale species and $67 \%$ of local-scale habitats) but for only half as much area $\left(-220 \mathrm{~km}^{2}\right.$, Fig. 3; see also Fig. 4). Of all the regional minsets, minset $\mathrm{H}$ is the one that achieved the best compromise between total area selected and incidental target achievement.

We used the average area selected by the three groups distinguished on the $\mathrm{x}$ axis of Figure 3 to fix the area to be selected by three random selections (R1, R2 and R3 in order of increasing area). Differences in target achievement between the random selections and their corresponding regional minsets were higher (up to $26 \%$ of features between HS and R2) when minsets targeted habitats (i.e. H, HS, HP and HSP; Fig. 3). Regional minsets targeting processes $(\mathrm{P})$ or species $(\mathrm{S})$ performed rather similarly to corresponding random selections (R3 and R1, respectively; Fig. 3).

\section{Features representation}

The regional minset targeting species (S) achieved targets for three species and two habitats at local scale. In the case of all the other regional minsets, the incidental target achievement of local-scale biodiversity features can be grouped in three categories: features meeting their targets under all circumstances, features never meeting their targets and features meeting their targets under certain circumstances. This was generally related to the amplitude of their conservation targets.

The biodiversity features that always met their targets incidentally were 10 of the 11 species with targets $\leq 30 \%$ and nine of the 11 habitats with targets $\leq 45 \%$. In general, they also met their targets in the random selections $\mathrm{R} 2$ and $\mathrm{R} 3$. In contrast, features with conservation targets $\geq 84 \%$ of their current extent never met their targets incidentally in regional minsets.

The three coastal species targeted at $100 \%$ at both scales, did not meet their targets in regional minsets targeting species. This was because of the incompleteness of both species datasets.

\section{The irreplaceability approach}

The spatial correlation between patterns of irreplaceability values of both scales was positive and varied 
(a) Species

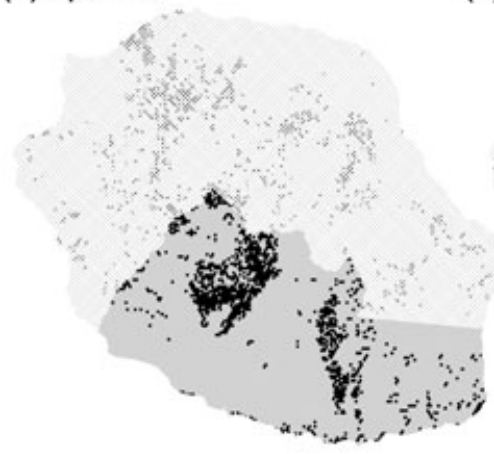

(b) Habitats+species+processes

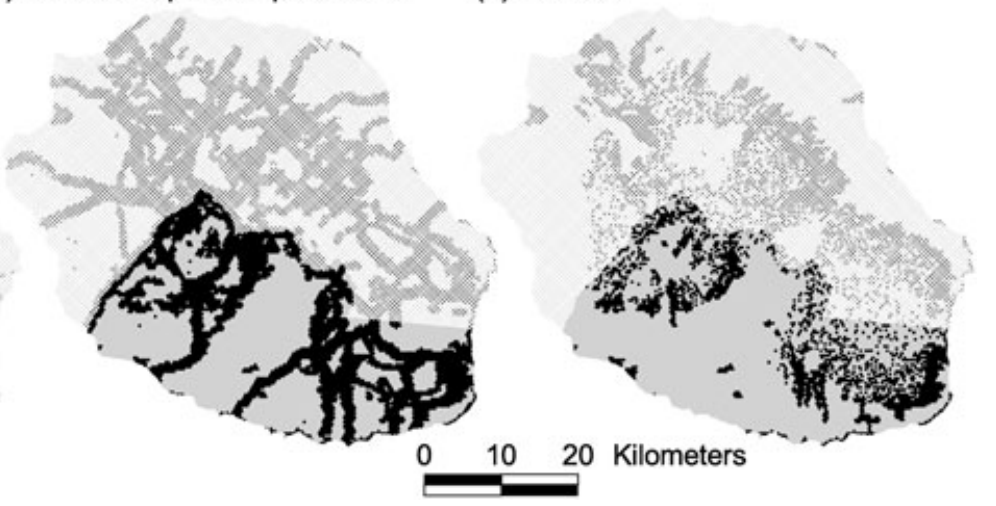

(c) Habitats

Fig. 4. Maps of the regional minsets that achieved the lowest (a) and the highest (b) incidental representation of biodiversity surrogates at local scale, and of the regional minset that achieved the best compromise between incidental representation, number of surrogates applied in the area-selection and total area selected (c). The planning units selected in each minset are shown in darker grey. The area outside the local planning domain is shaded.

Table 3. Spearman's rank correlation coefficients between the regional and local irreplaceability values

\begin{tabular}{|c|c|c|c|c|c|c|c|c|}
\hline & & \multicolumn{7}{|c|}{ Regional scale } \\
\hline & & $\mathrm{H}$ & S & $\mathrm{P}$ & HS & HP & SP & HSP \\
\hline \multirow[t]{7}{*}{ Local scale } & $\mathrm{H}$ & 0.94 & 0.36 & 0.49 & 0.88 & 0.57 & 0.49 & 0.57 \\
\hline & S & 0.63 & 0.34 & 0.40 & 0.60 & 0.41 & 0.40 & 0.40 \\
\hline & $\mathrm{P}$ & 0.45 & 0.35 & 0.80 & 0.47 & 0.76 & 0.79 & 0.76 \\
\hline & HS & 0.91 & 0.35 & 0.47 & 0.85 & 0.56 & 0.47 & 0.55 \\
\hline & $\mathrm{HP}$ & 0.55 & 0.37 & 0.77 & 0.57 & 0.81 & 0.76 & 0.80 \\
\hline & $\mathrm{SP}$ & 0.46 & 0.35 & 0.79 & 0.48 & 0.76 & 0.78 & 0.76 \\
\hline & HSP & 0.55 & 0.37 & 0.76 & 0.57 & 0.80 & 0.76 & 0.80 \\
\hline
\end{tabular}

Irreplaceability values were obtained from MARXAN summed solutions indicated by (a) letter(s) with $\mathrm{H}$ for habitats, $\mathrm{S}$ for species and $\mathrm{P}$ for processes of the surrogates used for the area-selection. Bold values indicate remarkable low and high coefficients.

from low (Spearman's rank correlation coefficient: $0.34)$ to very high (0.94; Table 3). Again, species were the least effective biodiversity surrogates applied at regional scale, as their irreplaceability values were always the least correlated with the irreplaceability values of all features at local scale (Table 3; see also Fig. 5b). In contrast, the irreplaceability values of regional scale habitats and processes (HP) were, on average, the most correlated with the irreplaceability values of all local-scale features (Table 3). The highest correlation was found between habitats of both scales (Table 3 and Fig. 5a). Finally, the correlation of the irreplaceability values of local-scale species (Fig. 5b) was generally low with the irreplaceability values of all regional scale biodiversity surrogates, but was the highest with regional scale habitats (Table 3 ).

\section{DISCUSSION}

Careful attention is needed to understand where finescale data will lead to marginally better conservation decisions (Conroy \& Noon 1996). This study indi- cated that regional assessments were relatively effective in achieving conservation targets for biodiversity surrogates at local scale, but that results varied depending on the type of biodiversity surrogates considered at regional or local scale. Area requirement also varied greatly between regional minsets depending on the biodiversity surrogates targeted, but was equivalent between analogous regional and local minsets. In general, the larger the tracts of land selected, the higher the incidental representation of biodiversity surrogates at local scale (Fig. 3). This illustrated the trade-off between level of representation and amount of land required (Wessels et al. 1999; Reyers et al. 2002).

\section{Species as biodiversity surrogates at a regional scale}

The issue of the effectiveness of species as biodiversity surrogates, in particular as cross-taxon indicators, has often been addressed in the conservation literature and is a complex one (see Reyers \& van Jaarsveld 2000; Reyers et al. 2000; Warman et al. 2004a). This study 


\section{(a) Maximum}
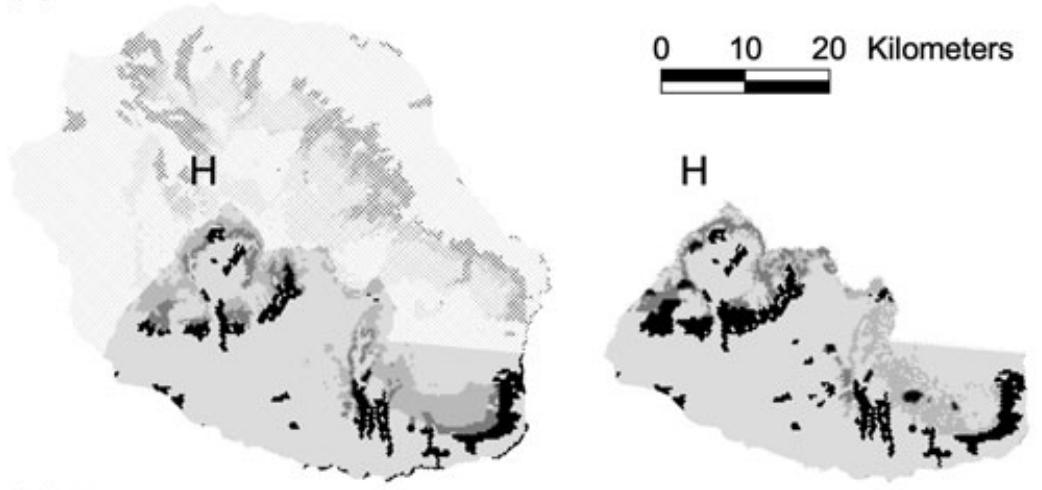

(b) Minimum
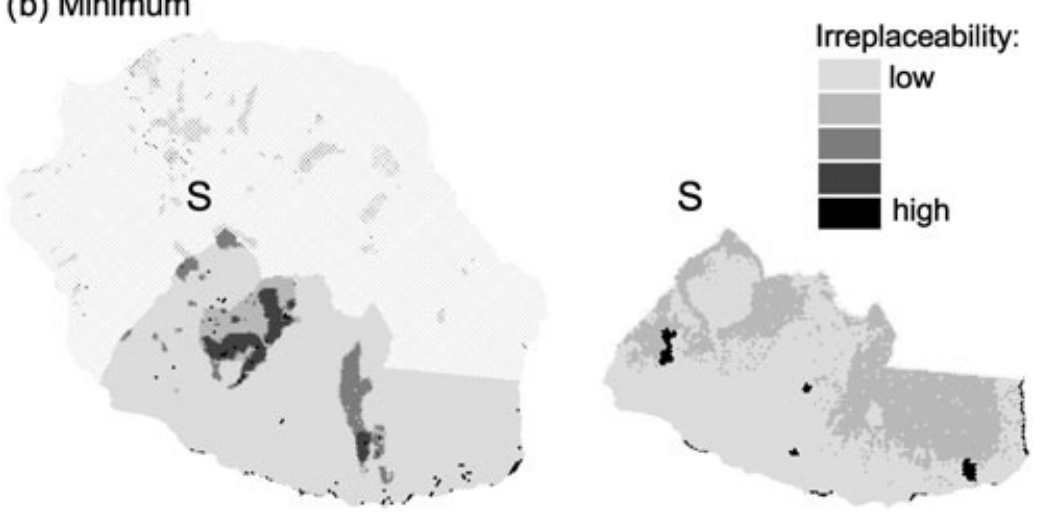

Fig. 5. Maps of the irreplaceability values for the maximum (between habitats at regional and local scale; a) and the minimum (between species at regional and local scale; b) Spearman rank correlation coefficients, when the regional and local MARXAN summed solutions were compared in pairs. The area outside the local planning domain is shaded.

confirms that targeting species at a regional scale proved to be a relatively ineffective surrogacy option for the incidental representation of most of the biodiversity features at local scale (see also Reyers et al. 2000; Warman et al. 2004b). The low spatial correlation between their irreplaceability values and those of all local-scale biodiversity surrogates further indicates that they stand little or no chance to incidentally represent local-scale biodiversity features at target level. The fact that the area requirement of a minset at a regional scale is inferior to the area requirement of a minset at a local scale is problematic, as the regional priority areas identified on the regional minset stands no chance to adequately represent all the biodiversity features at local scale. In particular, the inclusion of point localities in area-prioritizations increases site selection very marginally (Lombard et al. 2003), which suggests that their acquisition for regional planning represents a poor strategy.

\section{Habitats as biodiversity surrogates at a regional scale}

The best trade-off between a maximum representation and least area selected was obtained with the regional selection based on habitats. The high similarity between patterns of irreplaceability values of habitats at both scales might have been positively affected by the nestedness of the habitat classes. Nonetheless, as both habitat datasets differed in scale of thematic resolution but not in spatial resolution, the analysis demonstrated that the coarser habitat classes were efficient for a regional assessment in Réunion Island and that the acquisition of a detailed ecological knowledge for all a region's habitats is not a prerequisite (see also The incidental representation of biodiversity surrogates at local scale below). Habitats (or land types) are expedient biodiversity surrogates because they are relatively easy and inexpensive to derive and revise (Ferrier 2002; Pressey 2004) so they can be mapped over large areas. They are often defined by generalizations about environmental variation so are assumed to match the distribution of at least a proportion of species in a given region (Oliver et al. 2004; Pressey 2004; Stoms et al. 2005). As such, they usually insure a good incidental representation for at least widespread species (e.g. Wessels et al. 1999; Reyers et al. 2002; Lombard et al. 2003; Oliver et al. 2004; Stoms et al. 2005) as was also the case here. 


\section{Processes as biodiversity surrogates at a regional scale}

The findings clearly highlight that planning for patterns and processes considerably increases area requirement compared with planning for patterns only. Close to half the area of the local planning domain was necessary to represent processes in conservation networks. This, at the same time, insured a high incidental representation of species and habitats at local scale at target level, but overall proved a rather inefficient surrogacy option as its results for species and habitats were similar to randomly selecting planning units for an equivalent area. However, the integration of processes in area-prioritizations can be performed in a more efficient manner than was the case here. Here, all targets were fixed at 100\% of extant areas, but this might not be necessary for all processes. Besides, the configuration of some processes is spatially flexible (e.g. upland-lowland gradients) (Rouget et al. 2003) and when treated as such, their overlap with the distribution of important biodiversity patterns can be maximized. Finally, the areaselection protocol can be adapted in order to enhance the efficiency of the final conservation network. For instance, Cowling et al. (2003) designed a protocol in seven stages, where spatially fixed processes were integrated at stage two and two spatially flexible processes were integrated at stages five and six, respectively.

\section{The incidental representation of biodiversity surrogates at local scale}

The discrepancy observed between the distributions of three threatened coastal plant species analysed in this study highlights the difficulty of obtaining consistent distributions of imperilled species, and reliable species data in general (Reyers et al. 2001). Rather than undermining our results and conclusions, we believe that this discrepancy highlights the danger of solely relying on species data in conservation assessments. Indeed, the datasets used at both scales were obtained from sources that are commonly used in conservation planning (a botanical institute and a field technician with deep knowledge on the flora of this part of the island). It is likely that this impediment is inherent to many surrogacy analyses and conservation assessments based on species data, but that it was unmasked here because two independent datasets were used for the same taxa (see for instance Archaux et al. 2006). This underpins the need of intense field survey efforts for the mapping of species when species have to be used as biodiversity surrogates.

None of the processes identified for this assessment ever met their targets incidentally. This is the reason why they need to be explicitly tackled in conservation assessments (Pressey et al. 2003). While small-scale ecological and evolutionary processes can be captured when planning for the representation of biodiversity patterns (Rouget et al. 2003), the same does not apply to those processes that operate over large areas and in particular spatial configurations (Fairbanks \& Benn 2000; Desmet et al. 2002; Moritz 2002; Noss 2003). These processes usually are supported by geographic and environmental interfaces and gradients, and migratory corridors (e.g. Cowling \& Pressey 2001) and insure not only persistence of functional ecosystems, but also resilience to rapidly occurring climate change (IPCC 2007) by providing migratory pathways to new ecological niches (Hunter et al. 1988; Noss 2001).

Habitats and species at local scale with high percentage targets were typically those not reaching their targets incidentally in regional minsets. High targets usually concern threatened and/or rare species and fragmented and highly transformed habitats, the features generally in most urgent need of conservation. Rare and threatened biodiversity features have recurrently been missed in area-selections for other biodiversity surrogates (Reyers et al. 2002; Lombard et al. 2003; Rouget 2003; Warman et al. 2004a; Stoms et al. 2005). Threatened species are usually correlated to habitat loss, degradation and fragmentation (Wilcove et al. 1998; IUCN 2004; Ricketts et al. 2005). In Réunion Island, threatened species and degraded habitats were mostly in lowland areas, where most of the urban and agricultural activities were concentrated. As a result, we argue that the distribution of these imperilled biodiversity features could be conveniently predicted from accurate and fine-scale land cover information. Other threatened species (in particular birds) were restricted to less accessible parts of the landscape, where they were also associated to more cryptic threatening processes such as predation from introduced mammals (Probst et al. 2000). Therefore, the involvement of expert knowledge and the use of lists of threatened taxa should complement the use of fine-scale land cover data to help identify areas where effort should be focused for the fine-scale mapping of threatened biodiversity features.

\section{Concluding remarks: a spatial strategy to the choice of biodiversity surrogates in conservation assessments}

Our findings suggest that a spatial strategy based on a complementary set of biodiversity surrogates targeted at regional and local scale, respectively, can be an effective approach to conservation assessments. All three types of biodiversity surrogates were shown nec- 
essary for maximum biodiversity representation and persistence (Noss 1990; Fairbanks \& Benn 2000; Margules \& Pressey 2000), but in a manner characteristic of the coarse/fine filter approach. Coarse filters have been defined as ecosystem-type surrogates that typically insure the representation and persistence of widespread or cryptic species and ecosystem processes (Hunter et al. 1988; Noss 1996, 2002; Stoms et al. 2005); while fine filters usually are rare or imperilled species, assemblages and communities that are normally missed by coarse filters (Noss 2002; Stoms et al. 2005). Noss (2003) provides a good checklist to help identify these features. We highlight that the coarse and fine filters could typically be features defined at coarse and fine scale of thematic resolution, respectively. We also emphasize that coarse filters should also comprise spatial components for large-scale processes and we extend the definition of the fine filters to imperilled habitats. Our results supported that a spatial strategy consisting of targeting the coarse filters (processes included) at regional scale and the fine filters at local scale may be appropriate. New processes should be mapped if they can be identified at a higher level of detail for the local assessment. Fine-scale mapping and surveying effort for fine filters can be principally focused on transformed areas (Rouget 2003). Such a generalized framework could also be adapted with the incorporation of surrogates for wide-ranging species at regional scale where this is relevant (Poiani et al. 2000).

Fine filters usually are features under the most urgent need for conservation (Stoms et al. 2005). If opportunities to safeguard them arise, they should not be postponed until a regional assessment is accomplished. Thus, a foreseeable advantage of basing regional and local conservation assessments on complementary coarse and fine filters (Noss 2002) as proposed above is that undertaking these assessments independently in time should not impair the efficiency of the final conservation network significantly. Providing that assessments over larger areas are likely to increase the efficiency of conservation networks (Erasmus et al. 1999), regional assessments are necessary under all circumstances, and frameworks integrating conservation assessments across spatial scales are likely to be more the rule than the exception (e.g. The Nature Conservancy, http://www.nature.org).

The integrated approach proposed here needs to be more elaborated and further investigated. For instance, faunal distributions were not represented in our species dataset at local scale, while Lombard et al. (2003) found that habitats did not insure a good incidental representation of vertebrates and make recommendations on how to incorporate these data in the planning process. Finally, and more generally, the integration of conservation planning at multiple spatial levels is a topic that should receive more focus.

\section{ACKNOWLEDGEMENTS}

We thank the INTERREG-3B Project of Regional Partnership APIC-BIO (Accompagnement de la Planification Intégrée de la Conservation de la Biodiversité) 2005/2007, co-funded by the European Union (FEDER) and the Conseil Régional of Réunion Island. We are grateful to Jean Michel Probst and Nature et Patrimoine, the Office National des Forêts, the Conservatoire Botanique National des Mascarins (CBNM) and the Société d'Etudes Ornithologiques de la Réunion (SEOR) for the use of their datasets. Particular thanks to Eric Rivière for the time allocated at mapping new species data. Thank you to Dominique Strasberg and Thomas Le Bourgeois for inputs, and Luc Barbaro for useful advices.

\section{REFERENCES}

Archaux F., Gosselin F., Bergès L. \& Chevalier R. (2006) Effects of sampling time, species richness and observer on the exhaustiveness of plant censuses. F. Veg. Sci. 17, 299-306.

Bailey D., Billeter R., Aviron S., Schweiger O. \& Herzog F. (2007) The influence of thematic resolution on metric selection for biodiversity monitoring in agricultural landscapes. Landscape Ecol. 22, 461-73.

Baldwin D. J. B., Weaver K., Schnekenburger F. \& Perera A. H. (2004) Sensitivity of landscape pattern indices to input data characteristics on real landscapes: implications for their use in natural disturbance emulation. Landscape Ecol. 19, 25571.

Ball I. R. \& Possingham H. (2000) MARXAN (V1.8.2): marine reserve design using spatially explicit annealing, a manual. [Cited 12 August 2006.] Available from URL: http://www. ecology.uq.edu.au/marxan.htm

Baret S., Rouget M., Richardson D. M. et al. (2006) Current distribution and potential extent of the most invasive alien plant species on La Réunion (Indian Ocean, Mascarene islands). Austral Ecol. 31, 750-61.

Conservatoire Botanique National de Mascarin (CBNM) (2007) Index of vascular plants of Réunion Island: status, threats and protection levels. Version 2007.1. [Cited 24 November 2007.] Available from URL: http://flore.cbnm. org

Brooks T. M., Bakarr M. I., Boucher T. et al. (2004a) Coverage provided by the global protected-area system: is it enough? BioScience 54, 1081-91.

Brooks T. M., da Fonseca G. A. B. \& Rodrigues A. S. L. (2004b) Protected areas and species. Conserv. Biol. 18, 616-8.

Brooks T. M., da Fonseca G. A. B. \& Rodrigues A. S. L. (2004c) Species, data, and conservation planning. Conserv. Biol. 18, $1682-8$.

Cadet T. (1980) La végétation de l'île de La réunion, étude phytoécologique et phytosociologique (PhD Thesis). University of Aix Marseille, France.

Castilla G., Larkin K., Linke J. \& Hay G. J. (2009) The impact of thematic resolution on the patch-mosaic model of natural landscapes. Landscape Ecol. 24, 15-23.

Conroy M. J. \& Noon B. R. (1996) Mapping of species richness for conservation of biological diversity: conceptual and methodological issues. Ecol. Appl. 6, 763-73. 
Cowling R. M. \& Pressey R. L. (2001) Rapid plant diversification: planning for an evolutionary future. Proc. Natl. Acad. Sci. USA 98, 5452-7.

Cowling R. M., Pressey R. L., Lombard A. T., Heijnis C. E., Richardson D. M. \& Cole N. (1999) Framework for a conservation plan for the Cape Floristic Region (Report 9902). Institute of Plant Conservation, University of Cape Town.

Cowling R. M., Knight A. T., Faith D. P. et al. (2004) Nature conservation requires more than a passion for species. Conserv. Biol. 18, 1674-6.

Cowling R. M., Pressey R. L., Rouget M. \& Lombard A. T. (2003) A conservation plan for a global biodiversity hotspotthe Cape Floristic Region, South Africa. Biol. Conserv. 112, 191-216.

Crane P. et al. (2003) Measuring biodiversity for conservation: main report. Policy Document 11/03. The Royal Society, London. [Cited 11 June 2009.] Available from URL: http:// royalsociety.org/document.asp?tip $=0$ \&id $=1365$

Desmet P. G., Cowling R. M., Ellis A. G. \& Pressey R. L. (2002) Integrating biosystematic data into conservation planning: perspectives from southern Africa's succulent Karoo. Syst. Biol. 51, 317-30.

Driver A., Cowling R. M. \& Maze K. (2003) Planning for living landscapes: perspectives and lessons from South Africa. Center for Applied Biodiversity Science at Conservation International, Washington, DC; the Botanical Society of South Africa, Cape Town.

ESRI (Environmental Systems Research Institute), Inc. (19922002) ArcView GIS. (Version 3.2a). Redlands, CA.

Erasmus B. F. N., Freitag S., Gaston K. J., Erasmus B. H. \& van Jaarsveld A. S. (1999) Scale and conservation planning in the real world. Proc. R. Soc. Lond., Ser. B: Biol. Sci. 266, 315-9.

Fairbanks D. H. K. \& Benn G. A. (2000) Identifying regional landscapes for conservation planning: a case study from KwaZulu-Natal, South Africa. Landscape Urban Plan. 50, 237-57.

Ferrier S. (2002) Mapping spatial pattern in biodiversity for regional conservation planning: where to from here? Syst. Biol. 51, 331-63.

Ferrier S., Pressey R. L. \& Barrett T.W. (2000) A new predictor of the irreplaceability of areas for achieving a conservation goal, its application to real-world planning, and a research agenda for further refinement. Biol. Conserv. 93, 30325.

Ferrier S., Powell G. V. N., Richardson K. S. et al. (2004) Mapping more of terrestrial biodiversity for global conservation assessment. BioScience 54, 1101-9.

Higgins J. V., Ricketts T. H., Parrish J. D. et al. (2004) Beyond Noah: saving species is not enough. Conserv. Biol. 18, 167273.

Hortal J. \& Lobo J. M. (2006) Towards a synecological framework for systematic conservation planning. Biodivers. Informatics 3, 16-45.

Hunter M. L., Jacobson G. L. \& Thompson W. (1988) Paleoecology and the coarse-filter approach to maintaining biological diversity. Conserv. Biol. 2, 375-85.

IPCC (2007) The physical science basis of climate change: technical summary, a contribution of Working Group I of the Intergovernmental Panel on Climate Change. [Cited 12 November 2007.] Available from URL: http://ipcc-wg1. ucar.edu/wg1/wg1-report.html

IUCN (2004) 2004 IUCN Red List of Threatened Species. TM - a global species assessment: executive summary (eds J. E. M. Baillie, C. H. Taylor \& S. N. Stuart). [Cited 12 June
2009.] Available from URL: http://www.iucnredlist.org/ static/references

IUCN (2007) 2007 IUCN red list of threatened species. [Cited 24 November 2007.] Available from URL: http://www. iucnredlist.org

Jacquemyn H., Micheneau C., Roberts D. L. \& Pailler T. (2005) Elevational gradients of species diversity, breeding system and floral traits of orchid species on Réunion Island. $\mathcal{F}$. Biogeogr. 32, 1751-61.

Justus J. \& Sarkar S. (2002) The principle of complementarity in the design of reserve networks to conserve biodiversity: a preliminary history. F. Biosci. (Bangalore) 27, 421-35.

Kiester A. R. et al. (1996) Conservation prioritization using GAP data. Conserv. Biol. 10, 1332-42.

Knight A. T., Driver A., Cowling R. M. et al. (2006) Designing systematic conservation assessments that promote effective implementation: Best practice from South Africa. Conserv. Biol. 20, 739-50.

Lagabrielle E. (2007) Biodiversity conservation planning and territory modelling in Réunion island ( $\mathrm{PhD}$ Thesis). University of Réunion Island, France.

Larsen F. W. \& Rahbek C. (2005) The influence of spatial grain size on the suitability of the higher-taxon approach in continental priority-setting. Anim. Conserv. 8, 389-96.

Le Corre M. \& Safford R. J. (2001) La Réunion and Iles Eparses. Pisces Publications and BirdLife International, Newbury and Cambridge.

Le Corre M., Ollivier A., Ribes S. \& Jouventin P. (2002) Lightinduced mortality of petrels: a 4-year study from Réunion Island (Indian Ocean). Biol. Conserv. 105, 93-102.

Lombard A. T., Cowling R. M., Pressey R. L. \& Mustart P. J. (1997) Reserve selection in a species-rich and fragmented landscape on the Agulhas Plain, South Africa. Conserv. Biol. 11, 1101-16.

Lombard A. T., Cowling R. M., Pressey R. L. \& Rebelo A. G. (2003) Effectiveness of land classes as surrogates for species in conservation planning for the Cape Floristic Region. Biol. Conserv. 112, 45-62.

Margules C. R. \& Pressey R. L. (2000) Systematic conservation planning. Nature 405, 243-53.

Margules C. R., Pressey R. L. \& Williams P. H. (2002) Representing biodiversity: data and procedures for identifying priority area for conservation. f. Biosci. (Bangalore) 27, 30926.

Mittermeier R. A., Myers N. \& Thomsen J. B. (1998) Biodiversity hotspots and major tropical wilderness areas: approaches to setting conservation priorities. Conserv. Biol. 12, 516-20.

Molnar J., Marvier M. \& Kareiva P. (2004) The sum is greater than the parts. Conserv. Biol. 18, 1670-1.

Moritz C. (2002) Strategies to protect biological diversity and the evolutionary processes that sustain it. Syst. Biol. 51, 238-54.

Myers N., Mittermeier R. A., Mittermeier C. G., da Fonseca G. A. B. \& Kent J. (2000) Biodiversity hotspots for conservation priorities. Nature 403, 853-8.

Noss R. F. (1990) Indicators for monitoring biodiversity: a hierarchical approach. Conserv. Biol. 4, 355-64.

Noss R. F. (1996) Ecosystems as conservation targets. Tree 11, 351.

Noss R. F. (2001) Beyond Kyoto: forest management in a time of rapid climate change. Conserv. Biol. 15, 578-90.

Noss R. F. (2002) Information needs for large-scale conservation planning. Conservation Science, Inc. Ecological Monitoring and Assessment Network. 
Noss R. F. (2003) A checklist for wildlands network designs. Conserv. Biol. 17, 1270-5.

Oliver I., Holmes A., Dangerfield J. M. et al. (2004) Land systems as surrogates for biodiversity in conservation planning. Ecol. Appl. 14, 485-503.

Pence G. Q. K., Botha M. A. \& Turpie J. K. (2003) Evaluating combinations of on-and off-reserve conservation strategies for the Agulhas Plain, South Africa: a financial perspective. Biol. Conserv. 112, 253-73.

Poiani K. A., Richter B. D., Anderson M. G. \& Richter H. E. (2000) Biodiversity conservation at multiple scales: Functional sites, landscapes, and networks. BioScience 50, 133-46.

Pressey R. L. (2004) Conservation planning and biodiversity: assembling the best data for the job. Conserv. Biol. 18, 167781.

Pressey R. L. \& Nicholls A. O. (1989) Efficiency in conservation evaluation: scoring versus iterative approaches. Biol. Conserv. 50, 199-218.

Pressey R. L. \& Logan V. S. (1998) Size of selection units for future reserves and its influence on actual vs. targeted representation of features: a case study in western New South Wales. Biol. Conserv. 85, 305-19.

Pressey R. L. \& Taffs K. H. (2001) Scheduling conservation action in production landscapes: priority areas in western New South Wales defined by irreplaceability and vulnerability to vegetation loss. Biol. Conserv. 100, 355-76.

Pressey R. L., Humphries C. J., Margules C. R., Vane-Wright R. I. \& Williams P. H. (1993) Beyond opportunism: key principles for systematic reserve selection. Trends Ecol. Evol. 8, $124-8$.

Pressey R. L., Johnson I. R. \& Wilson P. D. (1994) Shades of irreplaceability - towards a measure of the contribution of sites to a reservation goal. Biodivers. Conserv. 3, 242-62.

Pressey R. L., Possingham H. P. \& Day J. R. (1997) Effectiveness of alternative heuristic algorithms for identifying indicative minimum requirements for conservation reserves. Biol. Conserv. 80, 207-19.

Pressey R. L., Cowling R. M. \& Rouget M. (2003) Formulating conservation targets for biodiversity pattern and process in the Cape Floristic Region, South Africa. Biol. Conserv. 112, 99-127.

Probst J. M., Le Corre M. \& Thebaud C. (2000) Breeding habitat and conservation priorities in Pterodroma baraui, an endangered gadfly petrel of the Mascarene archipelago. Biol. Conserv. 93, 135-8.

R Development Core Team (2007) R:A language and environment for statistical computing. R Foundation for Statistical Computing, Vienna. ISBN 3-900051-07-0. [Cited 17 October 2006.] Available from URL: http://www.R-project.org

Reyers B. \& van Jaarsveld A. S. (2000) Assessment techniques for biodiversity surrogates. S. Afr. F. Sci. 96, 406-08.

Reyers B., van Jaarsveld A. S. \& Kruger M. (2000) Complementarity as a biodiversity indicator strategy. Proc. R. Soc. Lond., Ser. B: Biol. Sci. 267, 505-13.

Reyers B., Fairbanks D. H. K., van Jaarsveld A. S. \& Thompson M. (2001) Priority areas for the conservation of South African vegetation: a coarse-filter approach. Divers. Distrib. 7, 79-95.

Reyers B., Wessels K. J. \& van Jaarsveld A. S. (2002) An assessment of biodiversity surrogacy options in the Limpopo Province of South Africa. Afr. Zool. 37, 185-95.
Ricketts T. H., Dinerstein D., Boucher T. et al. (2005) Pinpointing and preventing imminent extinctions. Proc. Natl. Acad. Sci. USA 102, 18497-501.

Rodrigues A. S. L. \& Gaston K. J. (2001) How large do reserve networks need to be? Ecol. Lett. 4, 602-09.

Rodrigues A. S. L., Gregory R. D. \& Gaston K. J. (2000) Robustness of reserve selection procedures under temporal species turnover. Proc. R. Soc. Lond., Ser. B: Biol. Sci. 267, 49-55.

Rouget M. (2003) Measuring conservation value at fine and broad scales: implications for a diverse and fragmented region, the Agulhas Plain. Biol. Conserv. 112, 217-32.

Rouget M., Cowling R. M., Pressey R. L. \& Richardson D. M. (2003) Identifying spatial components of ecological and evolutionary processes for regional conservation planning in the Cape Floristic Region, South Africa. Divers. Distrib. 9, 191-210.

Sarkar S. (2002) Defining 'Biodiversity'; assessing biodiversity. The Monist 85, 131-55.

Sarkar S. \& Margules C. (2002) Operationalizing biodiversity for conservation planning. F. Biosci. (Bangalore) 27 (Suppl 2), 299-308.

Sarkar S., Aggarwal A., Garson J., Margules C. R. \& Zeidler J. (2002) Place prioritization for biodiversity content. F. Biosci. (Bangalore) 27 (Suppl 2), 339-46.

Sarkar S., Justus J., Fuller T. et al. (2005) Effectiveness of environmental surrogates for the selection of conservation area networks. Conserv. Biol. 19, 815-25.

Sarkar S., Pressey R. L., Faith D. P. et al. (2006) Biodiversity conservation planning tools: present status and challenges for the future. Annu. Rev. Environ. Resour. 31, 123-59.

Smith R. J. (2004) Conservation Land-Use Zoning (CLUZ) software. Durrell Institute of Conservation and Ecology, UK.

Stoms D. M., Comer P. J., Crist P. J. \& Grossman D. H. (2005) Choosing surrogates for biodiversity conservation in complex planning environments. F. Conserv. Plan. 1, 44-63.

Strasberg D., Rouget M., Richardson D. M. et al. (2005) An assessment of habitat diversity and transformation on $\mathrm{La}$ Réunion Island (Mascarene Islands, Indian Ocean) as a basis for identifying broad-scale conservation priorities. Biodivers. Conserv. 14, 3015-32.

Warman L. D., Forsyth D. M., Sinclair A. R. E. et al. (2004a) Species distributions, surrogacy, and important conservation regions in Canada. Ecol. Lett. 7, 374-9.

Warman L. D., Sinclair A. R. E., Scudder G. G. E., Klinkenberg B. \& Pressey R. L. (2004b) Sensitivity of systematic reserve selection to decisions about scale, biological data, and targets: case study from Southern British Columbia. Conserv. Biol. 18, 655-66.

Warren B. H., Bermingham E., Prys-Jones R. P. \& Thebaud C. (2006) Immigration, species radiation and extinction in a highly diverse songbird lineage: white-eyes on Indian Ocean islands. Mol. Ecol. 15, 3769-86.

Wessels K. J., Freitag S. \& van Jaarsveld A. S. (1999) The use of land facets as biodiversity surrogates during reserve selection at a local scale. Biol. Conserv. 89, 21-38.

Wilcove D. S., Rothstein D., Dubow D., Phillips A. \& Losos E. (1998) Quantifying threats to imperiled species in the United States. Bioscience 48, 607-15.

Wilson K. A., McBride M. F., Bode M. \& Possingham H. P. (2006) Prioritizing global conservation efforts. Nature 440, 337-40. 